\title{
Entre maçãs e números: a sala de aula de matemática, políticas cognitivas e educação matemática ${ }^{1}$
}

\author{
Sônia Maria Clareto*
}

\begin{abstract}
Resumo
A proposta deste artigo é investigar políticas cognitivas praticadas na educação matemática junto a uma sala de aula. O que se pretende é problematizar as noções de cognição e de aprendizagem matemática na sala de aula, junto a relato cartográfico de evento em uma pesquisa de campo, em curso na investigação na qual este artigo se enreda. Neste evento, investigado segundo uma abordagem cartográfica, é travado um diálogo entre professora e alunos em torno da comparação de números. São destacadas as noções de práticas cognitivas e de aprendizagem, perspectivadas pela noção de invenção. O que se pretende é produzir uma torção nos modos de compreender e praticar a aprendizagem na educação matemática, trazendo para o debate uma compreensão de aprendizagem inventiva como constituição mútua si-matemática, a partir do encontro com Friedrich Nietzsche e Gilles Deleuze.

Palavras-chave: Aprendizagem inventiva; Filosofias da diferença; Comparação de números.
\end{abstract}

\section{Between apples and numbers: a classroom mathematics, cognitive policies and mathematics education}

\begin{abstract}
Entre maçãs e números: A sala de aula de matemática, políticas cognitivas e educação matemática

Não há nenhuma questão de dificuldade nem de compreensão: os conceitos são exatamente como sons, cores ou imagens, são intensidades que convêm a você ou não, que passam ou não passam. [...]. Não há nada a compreender, nada a interpretar.
\end{abstract}

The purpose of this paper is to investigate the cognitive policies practiced in mathematics education from a classroom. The aim is to problematize the notions of cognition and learning mathematics in the classroom, along with reporting cartographic event in a field research, ongoing research on which this article is entangled. In this event, investigated according to a cartographic approach, is engaged in dialogue between teacher and students around the comparison of numbers. Are highlighted notions of cognitive and practical learning, conceptualized by the notion of invention. The aim is to produce a torsional modes of understanding and practice learning in mathematics education, bringing the debate to an understanding of learning as inventive mutual self-constitution mathematics from the meeting with Friedrich Nietzsche and Gilles Deleuze.

Keywords: Inventive learning; Philosophies of difference; Compare numbers.

Gilles Deleuze

Maçã: o fruto pomáceo da macieira, árvore da família Rosaceae. As maçãs estão presentes em mitologias e religiões de muitas culturas, incluindo as tradições nórdica, grega e cristã. Em latim, a palavra "maçã" e "mal" são semelhantes (malum, "uma maçã", malum, "um mal, uma desgraça"). Isso também pode ter influenciado a maçã ter se tornando o "fruto proibido". Eva teria persuadido Adão a compartilhar com ela uma maçã.
Número: objeto da Matemática usado para descrever quantidade, ordem ou medida. O conceito de número está associado à capacidade de contar e comparar, para saber qual de dois conjuntos dados é o maior. Independentemente da natureza dos elementos de um conjunto, o número identifica a quantidade de elementos daquele dado conjunto. Número é uma ideia matemática, que expressa quantidade ou medida, na qual se abstrai a natureza dos objetos contados.

Número, na República de Platão:

"Ó admiráveis homens, a respeito de que números estais a discutir, entre os quais estão a unidade, tal como vós entendeis que existem, cada qual igual a outra, e sem diferir em nada, nem conter qualquer parte em si?" Que parece que eles responderiam? - Aqui está o que eu diria... Eles falam de números que só podem ser pensados e não podem ser tratados de outra maneira (PLATÃO, apud ARAÚJO JR, 2012, p. 469).

*Endereço eletrônico: sclareto@yahoo.com.br 
Um evento registrado durante a convivência em uma sala de aula. Professora e alunos de uma escola pública municipal na periferia de uma cidade mineira, envolvidos em uma pesquisa que busca pela matemática acontecendo na sala de aula.

Entre números e maçãs.

Assim como no Paraíso, a maçã confunde a razão, tenta a carne e quer afastar-nos - Adão e Eva, alunos do $6^{\circ}$ ano de uma escola municipal de uma cidade mineira - de uma verdade. A carne cede diante do vermelho da maçã, do seu aroma e sabor?

Pesquisar em uma sala de aula de matemática exige desnaturalizar um espaço desde há muito habitado, como aluno, como professor. É estar atento, à espreita, atentamente desatento, desatentamente atento.

Uma manhã, uma turma do $6^{\mathrm{a}}$ ano. Vinte e quatro alunos esparramam seus corpos pela aula. Para além de uma voz, nenhuma outra. Silêncio, movimentos contidos. A aula podia acontecer...

Professora: - Gente, como eu comparo números?

Não houve resposta.

Professora: - E como eu comparo duas maçãs?

Ela espera alguma resposta que não vem e, então, continua:- Bom, eu posso comparar duas maçãs pela cor, não posso? Dizer que uma está mais vermelha que a outra? Ou pelo peso? Uma maçã está mais pesada que a outra, ou pelo cheiro, pela textura, ou pelo tamanho. Existem vários modos de se comparar maçãs, não é mesmo?

O silêncio começa a ser quebrado pelo assentimento de alguns.

A professora refaz, então, a pergunta inicial: - Como se comparam dois números?

E emenda:

Professora: - Como eu comparo 8 e 5 ?

Um aluno: - Quando um é maior!

A professora assente e aguarda mais um pouco e mais dois alunos falam:

Outro aluno: 8 é par e 5 é ímpar.

Professora: - Não é comparação, né?

Ainda outro aluno: - Dividindo!

Professora: - Dividindo?

O tom da professora pareceu desencorajar o menino que havia sugerido a divisão.

A aula segue adiante e a professora dá continuidade ao seu projeto de ensinar comparação de números fracionários para aqueles alunos.

A proposta deste artigo é investigar políticas cognitivas praticadas na educação matemática junto a uma sala de aula. O que se pretende é problematizar as noções de cognição e da aprendizagem matemática na sala de aula, junto a um relato cartográfico de um evento de uma pesquisa de campo, em curso na investigação na qual este artigo se enreda. O termo problematização é pensado junto a Deleuze, em desdobramentos empreendidos por Kastrup, caracterizando-se por bifurcar, ou seja, criar caminhos divergentes. É na busca por bifurcar as noções de cognição e de aprendizagem que este artigo se coloca e, assim, abrir possibilidades de caminhos bifurcantes na educação matemática, investigando este movimento de diferenciação. A centralidade fica em como a cognição, constituindo um certo modo de produzir problemas, problematizar, acaba por circunscrever possibilidades de construir o mundo. Por isso, ao problematizar, não se está colocando em xeque a legitimidade dos estudos em torno de um dado objeto, mas perguntando por sua constituição e 
pelos efeitos que produz. O problema da invenção na educação matemática praticada na sala de aula também estará no foco deste artigo.

\section{A produção de relatos cartográficos em uma sala de aula de matemática}

A cartografia não é um método de pesquisa, no sentido mais usualmente entendido pela ciência como etapas e procedimentos para se chegar à verdade. Deleuze a trata como um princípio de funcionamento do conhecer, como uma prática do conhecer. Apropriando-se de uma terminologia da área da Geografia, Deleuze, em parceria com Guattari, constitui a cartografia para

[...] referir-se ao traçado de mapas processuais de um território existencial. Um território desse tipo é coletivo, porque é relacional; é político, porque envolve interações entre forças; tem a ver com uma ética, porque parte de um conjunto de critérios e referências para existir; e tem a ver com uma estética, porque é através dela como se dá forma a esse conjunto, constituindo um modo de expressão para as relações, uma maneira de dar forma ao próprio território existencial. Por isso, pode-se dizer que a cartografia é um estudo das relações de forças que compõem um campo específico de experiências (FARINA, 2008, p. 8-9).

A cartografia é, então, campo de invenção, movendo-se em suas dimensões ética, estética e política. Trata-se de dar voz aos fluxos de forças presentes no campo de pesquisa.

Uma sala de aula de matemática: a relação professor-aluno; os processos de ensinoaprendizagem, incluídas aí, as variáveis didáticometodológicas; os conteúdos matemáticos curriculares. Essa é uma sala de aula que todo o educador matemático (re)conhece, corresponde a uma imagem do que pensamos que seja a sala de aula. Assim, na sala de aula estão presentes os elementos: relação professor-aluno, conteúdo matemático, estratégias didático-metodológicas, relação aluno-aluno... Mas todos esses elementos são, já, formas. Foram constituídos em algum momento. Importa-nos perguntar pelo constituinte dessas formas. A cartografia aparece, então, como um modo investigativo que nos ajuda a acessar o constituinte das formas (PASSOS; KASTRUP;
ESCÓSSIA, 2009). Uma sala de aula de matemática é produzida, é inventada com todos os efeitos que ela dispara: subjetividades, aprendizagens, modos de estabelecer relações de conhecimento, matemática. O que a cartografia acaba por nos dar acesso é que os modos pelos quais as relações se estabelecem em uma sala de aula - e, de resto, em todo campo de pesquisa - são sempre singulares. A produção desta singularidade não tem sede no pesquisador como sujeito inventor, pois se apoia num substrato material dos acontecimentos daquela sala. Ao mesmo tempo, a sala de aula de matemática não é prévia ao processo de pesquisa, não é um objeto externo que informa coisas ao pesquisador e que pode ser, portanto, representada. A sala de aula de matemática se inventa no entre, na relação de conhecimento que tem por efeito a produção do pesquisador e de si própria. Suas singularidades são afirmadas nesse processo. É preciso, assim, um ethos do cuidado com a pesquisa que seja praticado a todo o instante e que garanta um rigor da cartografia.

Ter como campo de pesquisa uma sala de aula de matemática, portanto, implica em entendê-la como um coletivo de forças, ou seja, um espaço que se produz no movimento do plano das forças. Nesse sentido, nosso campo é composto por duas facetas, a do instituído e a do movente. Enquanto a primeira tende à estabilidade e ao reconhecimento da sala de aula; na segunda, um instituinte subjaz ao instituído como um movente, ou seja, como potência de diferenciação da sala de aula em formações outras que estão sempre se fazendo. É, enfim, pensá-la como sala-de-aula-de-matemática.

\section{Políticas cognitivas, invenção e aprendizagem na educação matemática}

Talvez possamos dizer que a educação matemática tem colocado o problema da aprendizagem em termos de representação, em sentido forte, na acepção de uma imagem universal do pensamento. Quer dizer, a aprendizagem como passagem ou transição natural e um estado de não saber para um estado de saber. Assim tem sido entendido o processo do conhecer. Esse conhecer se refere à produção de uma imagem mental para um objeto externo àquele que conhece: o sujeito do conhecimento. Essa "imagem mental" deve representar o objeto. O que pretendemos aqui é produzir uma torção neste modo de compreender e praticar a aprendizagem na educação matemática, a partir do encontro com Friedrich Nietzsche e Gilles 
Deleuze.

A filosofia moderna - de Descartes a Kant instituiu como figuras centrais das relações de conhecimento as categorias de sujeito e objeto. A crença na universalidade do conhecimento, que institui a forma do Mesmo, e pela partilha do bom senso, que institui a natureza reta do pensamento, tem por efeito pensá-lo enquanto um estado de coisas e não enquanto um processo. Sujeito e objeto são identidades, zonas ontológicas distintas que, em existindo, entram em relação. Nesse contexto, conhecer é representar, por meio do uso concordante das faculdades sobre um objeto suposto como o mesmo (DELEUZE, 2006). É nisso que a filosofia moderna implica: em conhecimento entendido como reconhecimento do mesmo, como inclinação reta do pensamento, como vontade de verdade.

Assim, se conhecer é representar - uma representação que se dá pelo uso concordante das faculdades de entendimento sobre um objeto suposto como o mesmo -, cognição se restringe à recognição. Tem-se, pois, a tríade: reconhecimentorepresentação-recognição. Tomar o objeto como mesmo, acaba por fundar uma Imagem Dogmática do Pensamento à qual tudo o que é representação se refere. Dessa maneira, as questões tratadas pelo estudo da cognição, pela psicologia cognitiva, são as das condições e do funcionamento da recognição. Quando partimos da caracterização da recognição, aprender é constituir uma representação para o mundo. Submetida, assim, a uma Imagem Dogmática do Pensamento, a aprendizagem é algo de caráter previsível e pode, portanto, ser modelada. $\mathrm{Na}$ educação escolar em geral, e na educação matemática em particular, esta parece ser a noção de aprendizagem mais comumente praticada. Aprender vincula-se, de modo indissociável, a ensinar: aprender é reter algum conhecimento ensinado por alguém (o professor, no mais dos casos) e "o processo educativo pode, então, ser tomado em uma perspectiva científica, dando segurança ao professor sobre como ensinar e como avaliar o aprendizado de cada aluno" (GALLO, 2012, p. 2). O que daí advém é que todos precisam aprender as mesmas coisas, do mesmo modo, ao mesmo tempo. A política cognitiva praticada nesse contexto é a política de recognição, que implica que o conhecimento se configura por regras e por saberes anteriores. Assim, a matemática é tomada como preexistente e o sujeito do conhecimento, como um eu centrado na racionalidade. Isso constitui uma educação matemática que opera com reprodução de conteúdos matemáticos em sala de aula. Diferentes educadores matemáticos têm se dedicado a discussões, críticas e problematizações em relação a essa prática de educação matemática. Entre outros: Ubiratan D’Ambrósio, Gelsa Knijnik, Maria da Conceição Fonseca, Dario Fiorentini, Maria Aparecida Bicudo, Rômulo Lins, Antonio Carlos Carreira de Souza. O que este artigo pode acrescentar ao debate é perspectivar a educação matemática na sala de aula, trazendo para o debate uma compreensão de constituição mútua si-matemática, ao interrogar a própria noção de matemática - área de saber, racionalidade, modo de pensar entre outros - e de sujeito - sujeito do conhecimento.

\section{$\sin$}

Uma pausa. Como assim, política cognitiva? Pensar em política cognitiva é propor a questão: que tipo de relação se estabelece com o conhecimento? Que tipo de relação se estabelece com a aprendizagem? Estas questões evidenciam mais o conhecer que o conhecimento. Ou seja, o conhecer referindo-se a uma ação, portando, em uma dimensão política. Quer dizer, o problema da cognição não é um problema somente teórico, mas, fundamentalmente, um problema político.

$O$ que o conceito de política cognitiva busca evidenciar é que o conhecer envolve uma posição em relação ao mundo e a si mesmo, uma atitude, um ethos. Sendo assim, o cognitivismo não é apenas um problema teórico, mas um problema político. Ele é uma das configurações que nossa cognição assume. Ele não dorme nas páginas dos livros, mas nos habita, e muitas vezes de maneira silenciosa. Os pressupostos do modelo da representação - a preexistência de um sujeito cognoscente e de um mundo dado a conhecer - são muitas vezes tão enraizadas em nós que se confunde com uma atitude natural. (KASTRUP, TEDESCO, PASSOS, 2008, p. 12, destaque nosso).

Ou seja, ao pressupor a existência prévia do sujeito cognoscente e do objeto que se dá a conhecer, o modelo da representação implica um modo de existir. Implica, digamos assim, uma cosmologia - a compreensão do mundo enquanto formas que se dão a conhecer e sujeitos conhecedores - e uma ontologia - uma certa 
compreensão do sujeito como sujeito do conhecimento.

Problematizar a naturalização desses pressupostos leva-nos a desacostumar o corpo que se coloca nesta atitude naturalizada. Desacostumar, neste caso, implica em proceder uma torção no modo como compreendemos o mundo: de um mundo dado à representação, que coloca os problemas que devem ser solucionados, para um mundo como efeito de práticas cognitivas. De uma política representativa para uma política inventiva.

Na perspectiva de uma política cognitiva da invenção, Kastrup (2007) vai propor uma noção de aprendizagem como coengendramento de si e do mundo. Entendida dessa maneira, a aprendizagem deixa de pressupor sujeito e objeto como polos a partir dos quais a cognição opera para considerá-los estabilizações provisórias da ação cognitiva, portadoras de uma inventividade intrínseca. É, assim, portanto, que sujeito e objeto são tirados de seu lugar de condição da cognição para serem pensados como efeitos provisórios dela. Aprendizagem como invenção de si e do mundo. É interessante ressaltar que a noção de invenção opera uma ampliação do conceito de cognição, ou seja, a invenção não é refratária à representação, mas opera nela uma torção fundamental. Por isso, a invenção não é o contrário da representação, mas guarda com ela uma relação de constituição e diferenciação.

Esta compreensão de cognição como coengendramento si-mundo, ou seja, a indissociabilidade sujeito e objeto, si e mundo, "é um convite a adotar uma certa maneira de estar no mundo, de habitar um território existencial e de se colocar na relação com o conhecimento" (KASTRUP, TEDESCO, PASSOS, 2008, p. 12-13). Trata-se, pois, de se colocar em uma outra relação com o conhecimento e com a aprendizagem matemáticos.

O que aqui se nomeia "invenção" não é o mesmo que criatividade. Comumente se associa criatividade a uma habilidade ou capacidade humana para resolução de problemas, propondo soluções inéditas. O que pretendemos, ao colocar o problema da invenção na educação matemática é pensar não a solução de problemas - criatividade mas a problematização - a invenção de problemas. Em outros termos,

A invenção é uma potência que a cognição tem de diferir de si mesma. Ela não é um processo psicológico a mais, além da percepção, do pensamento, da aprendizagem, da memória ou da linguagem, mas é uma potência temporal, potência de diferenciação, que perpassa todos os processos psicológicos. Colocando o problema da cognição a partir da invenção, falaremos então de uma percepção inventiva, de uma memória inventiva, de uma linguagem inventiva $e-o$ que é de particular interesse aqui - de uma aprendizagem inventiva (KASTRUP, 2005, 1274).

Aprendizagem inventiva. Como seria isso? Que aprendizagem? Como pensar a aprendizagem a partir da invenção? A aprendizagem aqui surge muito mais como processo de subjetivação, que aquisição de conhecimentos ou informações. Aprender é tornar-se. Aprendizagem como invenção de si. Correlata, simultânea e reciprocamente, a invenção de si implica a invenção do próprio mundo. Aprendizagem como problematização. Uma política cognitiva de invenção.

\section{$\operatorname{son}$}

Ora, a problematização, constituição de problemas, esbarra naquilo que para Deleuze constitui-se como o próprio ato de pensar: só pensamos em contato com um problema que nos força a pensar. $\mathrm{O}$ pensar não é natural ou espontâneo, ele só acontece diante de uma violência produzida por um problema. O pensamento como acontecimento singular.

imprevisível.

Aprendizagem como algo obscuro,

Essa imprevisibilidade do aprender joga por terra toda a pretensão da pedagogia moderna em ser uma ciência, a possibilidade de planejar, controlar, medir os processos de aprendizagem. Aquilo que a pedagogia controla é aquilo que o professor pensa que ensina, seu currículo, seus conteúdos e suas técnicas (GALLO, 2012, p. 4).

Essa noção de aprendizagem, em diálogo com os processos de "ensino-aprendizagem" da matemática escolar coloca em questão toda a sua dinâmica: que matemática está em pauta? Aquela entendida como um conjunto de regras que levam à verdade? O que acontece na sala de aula de matemática enquanto $\mathrm{o}$ professor - seguindo 
currículos que ditam conteúdos matemáticos a serem ensinados e avaliações de conteúdos a serem realizadas - pretende ensinar matemática?

Problematizar enunciados que parecem estar naturalizados e que, em efeito, são posicionados como "inquestionáveis" no campo pedagógico, nos permite experimentar a potencialidade de se "pensar diferentemente do que se pensa" verdades, que acabam funcionando como prescrições sobre como "devem" ser as práticas pedagógicas associadas ao ensinar $e$ ao aprender Matemática na escola. (KNIJNIK; DUARTE, 2009, p. 1).

\section{Entre maçãs e números: aprendizagens matemáticas}

Como a cognição inventiva pode nos ajudar a compreender a sala-de-aula-de-matemática? Talvez possamos apontar que a cognição inventiva nos ajuda a construir, em sala de aula, um espaço de problematização das formas cognitivas constituídas, pois

[...] somente entendendo a cognição como invenção podemos dar conta do fato de que algumas formas cognitivas, forjadas pelas nossas práticas concretas, resultam em subjetividades que encarnam o funcionamento inventivo, e outras resultam em subjetividades recognitivas, que se limitam a tomar o mundo como oferecendo informações prontas para serem captadas (KASTRUP, 2005, p. 1281).

Voltando à comparação de números, podemos dizer que são produzidos modos singulares de comparar números naturais, naquele espaço da sala-de-aula. Diante das negativas dos alunos em esquecer a maçã inicial e se fixar nos números, parece haver a manutenção de uma verdade: os diversos modos de comparar as maçãs não devem influenciar no modo único de comparar os números. Modo único? Ora, se tenho diferentes modos de comparar maçãs não poderiam ser constituídos diferentes modos de comparar números?

Vamos apontar para dois movimentos de ruptura, de resistência, que parecem espremer a maçã do fluxo cognitivo habitual, extraindo-lhe algum outro suco. $\mathrm{O}$ primeiro diz respeito à ideia de comparar números por meio dos conceitos de par e ímpar. A fala daquele aluno acaba por problematizar um certo modo de comparar números naturais, aquele esperado e desejado pela professora. A produção de uma matemática resiste ali: afinal, constitui-se um saber na comparação "8 é par e 5 é ímpar", ainda que isso não seja legitimado pela fala da professora. Ao falar que um é par e o outro ímpar, o aluno está comparando e ressaltando o que difere um do outro (o número par não pode ser ímpar e vice-versa). Enquanto que em " 8 é maior que 5", o que está em jogo é uma hierarquização numérica, uma ordinalidade. Ao usar um qualificador, a noção de que os naturais podem ser pares ou ímpares, o aluno coloca em movimento um quantificador, 8 é maior que 5 . Sim, 8 é maior que $5, e$ também 8 é par e 5 é ímpar. O número ganha uma certa coloração avermelhada da maçã?

O segundo refere-se à comparação pela divisão. Houve uma estranheza: posso comparar números dividindo???. Sim, dividindo. Se o quociente é menor que 1, temos que o dividendo é menor que o divisor; se o quociente é exatamente 1 , o dividendo e o divisor são iguais; enquanto que se o quociente for maior que 1 , o dividendo é menor que o divisor - diz uma voz de uma matemática. Uma voz de um aluno poderia expressar: uai, se dividir 8 por 5 , posso saber quantas vezes o cinco cabe dentro do 8. Como cabe uma vez, e mais um pouco, o 8 é maior. Se coubesse menos de uma vez, o 5 seria maior. Se fosse zero, os dois seriam iguais. $\mathrm{O}$ número ganha um certo gosto azedo-doce da maçã?

A matemática que é produzida nesta salade-aula não se constitui fora da matemática acadêmica e dos saberes escolares curriculares, tampouco os nega. Ao contrário, opera em seu interior por meio de um movimento de diferenciação e produz formas que não podem ser antecipadas, previstas. Entretanto, o que está em jogo é o modo como a maquinaria da educação matemática opera e faz operar a sala de aula. A questão é antes: como funciona a matemática escolar? Essa questão faz um sentido junto aos estudos empreendido por Moreira e Davi (2005; 2011), mas não iremos nos ater aqui a essa discussão. Não se trata, então de perguntar: o que é a matemática escolar? Uma vez que "o que é" remete à essência daquilo que é e aí estaríamos no campo de uma analítica da verdade que produz modelos morais e moralizantes de conhecimento. Por outro lado, o "como funciona" opera na dinâmica do processo de constituição, na processualidade da produção daquela sala de aula. 
Esse é um ponto chave a ser considerado: as políticas cognitivas que instauram modelos representacionais operam segundo uma vontade de verdade. Desse modo, fazer operar a invenção, cultivar uma política cognitiva que a leve em conta, é colocar em questão essa vontade de verdade. Enquanto a vontade de verdade opera com modelos pautados por uma verdade universal, com vistas a uma universalização, a introdução do problema da invenção leva à negação dos universais e, portanto, a um investimento na imanência. O que está acontecendo naquela sala de aula, naquele momento? É a invenção operando, silenciosa e vibrátil, naqueles corpos.

A invenção opera, pois, a todo tempo naquela sala-de-aula-de-matemática, bifurcando, operando escapes para aquilo que a professora, o programa, os conteúdos matemáticas mostram como formas já dadas. A invenção atua desacostumando professora, alunos e pesquisador. Desacostumandoos de suas funções, de seus pensares, de suas verdades.

Podemos dizer que aqueles alunos ao ensaiaram uma dissidência, ensaiaram um "lugar de pensador", se com Nietzsche compreendermos que o que constitui o pensador é sua incapacidade de guardar distância e indiferença em face de uma abstração. Nietzsche, em um fragmento de outubro de 1880, afirma que "A incapacidade de guardar em face de uma abstração a sua distância e a sua indiferença, eis o que constitui o pensador" (NIETZSCHE apud SÉVÉRAC, 2009, p. 42). Quer dizer: o pensar não se constitui de abstrações, mas ao contrário, começa no movimento que a abstração pode constituir. $\mathrm{O}$ pensamento não está no número que elimina a cor, o cheiro, o sabor, a massa... - mas no movimento que a maçã - com seu avermelhadosangue, com sua acidez-doce, com seu ruídosuculento ao ser mordida... - produz no número, na abstração numérica.

Número: abstração da maçã?

A abstração elimina não só a maçã, mas também o corpo que se apetece pela cor avermelhada da maçã, pelo seu cheiro e até pelo ruído suculento de uma mordida. Elimina o corpo. Elimina o corpo que experiência a maçã. Elimina o corpo que experiência o número. Elimina o corpo que conhece.

O corpo é eliminado, resta o número.

Mas os corpos continuam operando: experimentando, se inquietando, mordendo a maçã, mordendo o número. A invenção promove esse desassossego, essa vibração. O corpo nunca é eliminado por completo. Algo sempre resta de pulsação. Algo sempre resta de sangue. O sujeito do conhecimento, pensado como o sujeito universal do conhecimento, este sujeito cognoscente não está totalmente abrigado do intempestivo, do improvável. Ele é também corpo-que-conhece, corpo-que-pensa. É cognição e carne. Cognição e sangue. Cognição carnada corpo.

(Um)a educação matemática, então, segue sendo praticada naquela sala de aula, por professora e alunos. Poderíamos dizer que, no caso da comparação de números, naquela sala de aula, alunos artistaram a matemática ao propor as respostas não esperadas pela professora. Fomos, e seguimos sendo, afetados pelas inquietações daquele momento. Outros modos de comparar números, incorporando as respostas dos alunos, vão nascendo. Uma educação matemática que restaura o corpo e o lugar do corpo na matemática se contorce por entre as políticas cognitivas praticadas naquela sala de aula.

Enfim, o que resta de uma sala-de-aula-dematemática quando a aula se encerra é aquilo que em cada um de nós se fez inquietação. O que resta de uma sala-de-aula-de-matemática é a política cognitiva praticada naquele território existencial.

\section{Nota}

1 Agradecimentos ao Programa de Pós-Graduação em Educação da Universidade Federal de Juiz de Fora PPGE/UFJF.

\section{Referências}

ARAUJO JR., Anastácio Borges de. A natureza dos números na República de Platão. Kriterion [online]. 2010, vol.51, n.122, pp. 459-471.

DELEUZE, G. Diferença e repetição. Rio de Janeiro: Graal, 2006.

FARINA, C. Arte e formação: uma cartografia da experiência estética atual. In: Anais da 31 ${ }^{\mathbf{a}}$ Reunião da ANPED. Caxambu, 2008.

GALLO, Sílvio. As múltiplas dimensões do aprender. In: Anais Congresso de Educação Básica: aprendizagem e currículo. Florianópolis, 2012. Disponível em http://www.pmf.sc.gov.br/arquivos/arquivos/pdf/13 
02_2012_10.54.50.a0ac3b8a140676ef8ae0dbf32e66 2762.pdf. Acesso em 07 abril 2012.

KASTRUP, V. A invenção de si e do mundo: uma introdução do tempo e do coletivo no estudo da cognição. Belo Horizonte: Autêntica, 2007.

KASTRUP, V. Políticas Cognitivas na Formação do Professor e o Problema do Devir-Mestre. In: Educação \& Sociedade, v.26 n.93. Campinas: Cedes, 2005, p.1273-1288.

KASTRUP, V.; TEDESCO, S.; PASSOS, E. Políticas da Cognição. Porto Alegre: Sulina, 2008.

KNIJNIK, G.; DUARTE, C.G. Entrelaçamentos e dispersões de enunciados no discurso da educação matemática: um estudo sobre a importância de trazer a 'realidade' para as aulas de matemática. Anais da 32 ${ }^{\text {a }}$ Reunião Anual da Anped, 2009. Disponível em http://www.anped.org.br/reunioes/32ra/arquivos/.../
GT19-5180--Int.pdf. Acessado em janeiro de 2012.

MOREIRA, P. C.; DAVID, M. M. M. S. Matemática escolar, matemática científica, saber docente e formação de professores. Zetetike, v.11, n.19, 2011, pp. 57-80.

MOREIRA, P. C.; DAVID, M. M. M. S. A formação matemática do professor: licenciatura e prática docente. Belo Horizonte: Autêntica, 2005. 120p. (Tendências em Educação Matemática, 11).

PASSOS, E.; KASTRUP, V.; ESCÓSSIA, L. (orgs). Pistas do método da cartografia: pesquisaintervenção e produção de subjetividade. Porto Alegre: Sulina, 2009.

SÉVÉRAC, P. Conhecimento e afetividade em Spinoza. In: MARTINS (org.) O mais potente dos afetos: Spinoza e Nietzsche. São Paulo: Martins Fontes, 2010, pp. 17-36.

\section{Sobre a autora:}

Sônia Maria Clareto: Universidade Federal de Juiz de Fora, Juiz de Fora, MG. 